\title{
Vaccine Hesitancy in Patients With Multiple Sclerosis
}

\section{Preparing for the SARS-CoV-2 Vaccination Challenge}

Lara Diem, MD, Christoph Friedli, MD, Andrew Chan, MD, Anke Salmen, PD, MD, and Robert Hoepner, PD, MD

Neurol Neuroimmunol Neuroinflamm 2021;8:e991. doi:10.1212/NXI.0000000000000991
Correspondence

Dr. Diem

larafrancesca.diem@insel.ch

\begin{abstract}
\section{Objective}

Vaccine hesitancy is a complex public health issue referring to concerns about safety, efficacy, or need for vaccination. Using pneumococcal vaccination, which is recommend in anti-CD20treated multiple sclerosis (MS) patients, as a model, we assessed vaccination behavior in patients with MS to prepare for the upcoming SARS-CoV-2 vaccination challenge.
\end{abstract}

\section{Methods}

By a medical chart review, we retrospectively identified patients with MS treated with ocrelizumab at the University Hospital Bern in 2018-2020. Pneumococcal vaccination was discussed with the patients during clinical visits and highlighted in the after-visit summary addressed to the general practitioner before ocrelizumab initiation as part of our clinical standard of care.

\section{Results}

Pneumococcal vaccination was performed in 71/121 (58.7\%) of patients, and 50/121 (41.3\%) patients were not vaccinated. Patients who did not get a pneumococcal vaccination were younger (no vaccination vs vaccination; mean [95\% CI] 40.1 [36.1-44.1] vs 45.4 [41.9-48.8], $p$ $=0.028$ ) and had more frequently a relapsing remitting disease course (no vaccination vs vaccination, $\mathrm{n}$ [\%]; 43/50 [86.0\%] vs 49/71 [69.0\%], $p=0.031$ ). Furthermore, patients who did not get vaccination had more frequently a history of comorbid psychiatric disorder (no vaccination vs vaccination, $\mathrm{n}(\%) ; 12 / 50[24.0]$ vs $7 / 71[9.8], p=0.035)$.

\section{Conclusion}

Our study demonstrated that in our single-center cohort, $41.3 \%$ of patients with MS do not get the recommended pneumococcal vaccination. Future research should focus on vaccine hesitancy in the vulnerable cohort of patients with MS to improve the safety of MS immunotherapies. 


\section{Glossary}

CAM = complementary and alternative medicine; EDSS = Expanded Disability Status Scale; FOPH = Federal Office of Public Health; $\mathbf{M S}=$ multiple sclerosis; $\mathbf{O C R}=$ ocrelizumab.

Vaccine hesitancy is a complex public health issue referring to concerns about the safety, efficacy, or need for vaccination. ${ }^{1}$ Each year, Streptococcus pneumoniae is estimated to cause more than 1,000 serious infections in Switzerland. ${ }^{2}$ Patients with multiple sclerosis (MS) treated with ocrelizumab (OCR, Ocrevus, Roche, Basel, Switzerland) are at risk of S. pneumoniae infections. The Swiss Federal Office of Public Health (FOPH) recommends pneumococcal vaccination in patients treated with immunosuppressants including OCR ${ }^{3}$ Using pneumococcal vaccination as a model, we aimed to assess vaccination behavior in patients with MS to prepare for the upcoming SARS-CoV-2 vaccination challenge.

\section{Methods}

By a medical chart review, we retrospectively identified patients with MS treated with OCR at the University Hospital Bern in 2018-2020 leading to a cohort of 166 patients. Of 166 patients, 45 patients were excluded because of missing clinical information regarding vaccination status because of the retrospective nature of our study, resulting in a cohort of 121 patients (table e-1, links.lww.com/NXI/A466). Pneumococcal vaccination was recommended as indicated per FOPH guidelines, ${ }^{3}$ discussed with the patients during clinical visits, and highlighted in the after-visit summary addressed to the general practitioner before OCR initiation as part of our clinical standard of care.

The following variables were extracted from medical records: age, sex, Expanded Disability Status Scale (EDSS), MS diagnosis, type of MS, disease modifying therapies before switching, time of vaccination, reason for missing vaccination, clinical relapse before OCR start, MRI activity-defined as gadolinium-enhancing lesion and/ or new/enlarging T2 lesion-1 year before/after start of therapy/vaccination, and concomitant psychiatric disorders. Continuous variables are presented as mean and 95\% CIs, whereas categorical variables are reported as frequencies. Continuous variables are compared using MannWhitney $\mathrm{U}$ and Wilcoxon signed rank tests and categorical variables with the $\chi^{2}$ test.

\section{Standard Protocol Approvals, Registrations, and Patient Consents}

The study was approved by the Cantonal Ethics Committee (KEK-BE \#2017-01369).

\section{Data Availability}

Anonymized source data are available upon reasonable request via the corresponding author.

\section{Results}

Patients were 43.2 years old (mean, 95\% CI 40.6-45.8), predominantly female $75 / 121(62.0 \%)$, and had a moderate degree of disability (mean EDSS (95\% CI): 3.1 (2.8-3.4); table 1).

Pneumococcal vaccination was performed in $71 / 121$ (58.7\%) of patients in mean 4.0 weeks before first dose of OCR (95\% CI $0.2-7.8$ ) with a range of 46.44 weeks before and 68.53 weeks after first dose OCR. In total, 50/121 (41.3\%) patients were not vaccinated. In these 50 patients, the reasons for lack of vaccination were as follows: lack of adherence to vaccination recommendations $(n=30)$, MS disease activity $(n=11)$, general vaccination recommendation (not specifically for pneumococcal vaccine) in after-visit summary addressed to the general practitioner $(\mathrm{n}=8)$, and unexpected pregnancy $(\mathrm{n}=1)$.

Patients who did not get a pneumococcal vaccination were younger (no vaccination vs vaccination; mean [95\% CI] 40.1 [36.1-44.1] vs 45.4 [41.9-48.8], $p=0.028)$ and had more frequently a relapsing remitting (RR) disease course (no vaccination vs vaccination, $\mathrm{n}[\%] ; 43 / 50$ [86.0\%] vs $49 / 71$ $[69.0 \%], p=0.031)$. Furthermore, patients who did not get a pneumococcal vaccination had more frequently a history of comorbid psychiatric disorder (no vaccination vs vaccination, n [\%]; $12 / 50$ [24.0] vs 7/71 [9.8], $p=0.035)$ including depression $(n=8)$, psychosis $(n=2)$, history of drug abuse ( $n$ $=1)$, and borderline personality disorder $(n=1)$ in those without vaccination.

MS immunotherapies before initiation of OCR had an impact on vaccination behavior: untreated patients with MS were vaccinated more frequently compared with treated patients with MS (14/50 [28.0\%] vs 34/71 [47.8\%], $p=0.028)$. Clinical and MRI disease activity within 12 months before OCR did not differ between patients with and without vaccination. Initiation of OCR resulted in a reduction of disease activity in both patient cohorts. Because date of vaccination differs from date of first OCR treatment, we also investigated in the subgroup of vaccinated MS patients for clinical and radiologic disease activity within 1 year before and after vaccination, which demonstrates a similar reduction of disease activity after OCR compared with the whole cohort (table 1).

\section{Discussion}

Our study demonstrated that in our single-center cohort, 41.3\% of patients with MS do not get the recommended pneumococcal vaccination before initiation of OCR. Those 
Table 1 Patient Characteristics Concerning Pneumococcal Vaccination Status

\begin{tabular}{|c|c|c|c|}
\hline \multicolumn{3}{|l|}{ Variable } & All patients $(n=121)$ \\
\hline \multicolumn{3}{|l|}{ Female, $\mathrm{n}(\%)$} & $75 / 121(62.0)$ \\
\hline \multicolumn{3}{|l|}{ Age $(y)$, mean $(95 \% \mathrm{Cl})$} & $43.2(40.6-45.8)$ \\
\hline \multicolumn{4}{|l|}{ MS type, $n(\%)$} \\
\hline \multicolumn{2}{|l|}{ RRMS } & & $92 / 121(76.0)$ \\
\hline \multicolumn{2}{|l|}{ PPMS } & & 29/121 (24.0) \\
\hline \multicolumn{2}{|l|}{ EDSS, mean $(95 \% \mathrm{Cl})$} & & $3.1(2.8-3.4)$ \\
\hline \multicolumn{2}{|l|}{ Disease duration $(\mathrm{y})$, mean $(95 \% \mathrm{Cl})$} & & $6.5(5.3-7.7)$ \\
\hline \multicolumn{4}{|l|}{ DMT before switch } \\
\hline \multicolumn{2}{|l|}{ No medication } & & 48/121 (39.7) \\
\hline \multicolumn{2}{|l|}{ First-line treatment } & & 26/121 (21.5) \\
\hline \multicolumn{2}{|l|}{ Second-line treatment } & & $47 / 121(38.8)$ \\
\hline \multicolumn{2}{|l|}{ Vaccinated patients } & & $71 / 121(58.7)$ \\
\hline \multicolumn{2}{|c|}{ Time between vaccination and first OCR dose $(\mathrm{wk})$, mean $(95 \% \mathrm{Cl})$} & & $4.0(0.2-7.8)$ \\
\hline \multicolumn{4}{|l|}{ Reason for being unvaccinated } \\
\hline \multicolumn{2}{|c|}{ Lack of adherence to vaccination recommendations } & & $30 / 50(60.0)$ \\
\hline Only general vaccination recommendation & & & $8 / 50(14.0)$ \\
\hline Disease activity & & & $11 / 50(22.0)$ \\
\hline Pregnancy & & & $1 / 50(2.0)$ \\
\hline Variable & With vaccination $(n=71)$ & Without vaccination $(n=50)$ & $p$ Value \\
\hline Female, $\mathbf{n}(\%)$ & $43 / 71(60.6)$ & $32 / 50(64.0)$ & 0.701 \\
\hline Age $(y)$, mean $(95 \% \mathrm{Cl})$ & $45.4(41.9-48.8)$ & $40.1(36.1-44.1)$ & 0.028 \\
\hline EDSS, mean $(95 \% \mathrm{Cl})$ & $3.1(2.7-3.5)$ & $3.0(2.5-3.5)$ & 0.793 \\
\hline RRMS, n (\%) & $49 / 71(69.0)$ & $43 / 50(86.0)$ & 0.031 \\
\hline Disease duration $(\mathrm{y})$, mean $(95 \% \mathrm{Cl})$ & $6.1(4.4-6.8)$ & $6.8(5.0-8.5)$ & 0.916 \\
\hline No medication, $\mathrm{n}(\%)$ & $34 / 71(47.9)$ & $14 / 50(28.0)$ & 0.028 \\
\hline First-line treatment, $n(\%)$ & $12 / 37(32.4)$ & $14 / 36(38.9)$ & 0.565 \\
\hline Second-line treatment, $\mathbf{n}(\%)$ & $25 / 37(67.6)$ & $22 / 36(61.1)$ & 0.565 \\
\hline Psychiatric disorder, $n(\%)$ & $7 / 71(9.8)$ & $12 / 50(24.0)$ & 0.035 \\
\hline Clinical relapse 12 mo before OCR start, $n(\%)$ & $19 / 71(26.8)$ & $16 / 50(32.0)$ & 0.531 \\
\hline Clinical relapse 12 mo after OCR start, $n$ (\%) & $0 / 71$ & $0 / 50$ & 1.0 \\
\hline MRI activity 12 mo before OCR start, $n(\%)$ & $30 / 62(48.4)$ & $26 / 45(57.8)$ & 0.337 \\
\hline MRI activity 12 mo after OCR start, $n(\%)$ & $0 / 49$ & $1 / 32$ & 0.213 \\
\hline Variable & 1 year before OCR $(n=121)$ & 1 year after OCR $(n=121)$ & $p$ Value \\
\hline Clinical activity, n (\%) & $35 / 121(28.9)$ & 0/121 (0) & $<0.001$ \\
\hline MRI activity, $n(\%)$ & $56 / 107(52.3)$ & $1 / 81(0)$ & $<0.001$ \\
\hline Variable & 1 year before vaccination $(n=71)$ & 1 year after vaccination $(n=71)$ & $p$ Value \\
\hline Clinical activity, n (\%) & $19 / 71(26.8)$ & 0/71 (0) & $<0.001$ \\
\hline MRI activity, $\mathbf{n}(\%)$ & $30 / 62(48.4)$ & $0 / 49(0=)$ & $<0.001$ \\
\hline
\end{tabular}

Abbreviations: DMT = disease modifying therapy; EDSS = Expanded Disability Status Scale; $\mathrm{n} . \mathrm{a}=$ not applicable; OCR = ocrelizumab; PPMS = primary progressive multiple sclerosis; RRMS = relapsing remitting multiple sclerosis.

MRI activity was defined as the presence of gadolinium-enhancing lesion/s and/or new or enlarging T2 lesion/s on cMRI.

Statistics: Continuous variables are presented as mean and $95 \% \mathrm{Cls}$, whereas categorical variables are reported as frequencies. Continuous variables are compared using Mann-Whitney $U$ and Wilcoxon signed rank tests and categorical variables with the $\chi^{2}$ test. Significant $p$ values are highlighted in bold letters. 
patients were younger and had more frequently an RR disease course and a psychiatric comorbidity. This finding may be related to the behavior of young people toward vaccination. Often, young people argue that the corresponding diseases do not affect them and that the risk is mainly in older people.

Moreover, patients with use of disease-modifying treatments before initiation of OCR, which should not influence the decision to vaccinate against $S$. pneumoniae, did get vaccinations less frequently compared with untreated patients. MS disease activation after pneumococcal vaccination could not be observed neither in clinical relapses nor in MRI disease activity. These findings are crucial because the fear of disease activity is a main argument against vaccination in people with MS. ${ }^{4}$ This study showed that vaccine hesitancy remains a widespread problem in our monocentric cohort. Vaccine hesitancy is defined as the delay in acceptance or refusal of vaccination despite the availability of vaccination services. ${ }^{5}$ Vaccine hesitancy is an individual behavior influenced by a range of factors, such as knowledge or experiences in the past. The absence of awareness about "who and why" one should be vaccinated and selfestimated (in)sufficiency of information about vaccination is frequently associated with vaccination decisions. ${ }^{6}$ Perceived importance of vaccination is an individual determinant of vaccine adherence. Individuals who refuse or are hesitant regarding vaccination often have an own worldview regarding health (e.g., importance of natural immunity). ${ }^{7}$ Similarly, the increasing popularity of complementary and alternative medicine (CAM) plays an important role in the vaccination skepticism of the population. In fact, refusal of vaccination is significantly more frequent among CAM-users than among nonusers. Patients who consulted physicians practicing herbal medicine, anthroposophical medicine, or homeopathy reported the highest frequencies of vaccination refusal. ${ }^{8}$ In addition, experiences with vaccinations in the past can influence future decision-making regarding vaccination. Vaccine hesitancy can also be the result of broader influences and should always be looked at in the historical, political, and sociocultural context in which vaccination is discussed. The trust placed in the healthcare system, in the doctors who recommend and administer vaccines, and in the different types of vaccine information conveyed by the media plays an important role in the decision to be vaccinated. ${ }^{9}$ Unfortunately, vaccine misinformation on major social media companies is a common problem, and the companies are facing wide criticism for failing to deal with vaccine misinformation on their platforms. Especially in the light of the newly available COVID-19 vaccine, misinformation on social media is undoubtedly going to pose a serious barrier to uptake. ${ }^{10}$ The Strategic Advisory Group of Experts on Immunization Working Group discussed that poor communication of healthcare professionals plays an important role in the vaccine hesitancy. When communication of healthcare professionals is poor or inadequate, it can negatively influence vaccination uptake and contribute to vaccine hesitancy. ${ }^{5}$ Therefore, clear and targeted education, also taking into account social media, about vaccination is imperative. Obviously, we cannot extrapolate these data concerning pneumococcal vaccination without further ado on the now available COVID-19 vaccination. However, our short retrospective observation with all limitations inherent of the design highlights the fact that physicians caring for people with MS should proactively initiate vaccination discussions with their patients and follow up on the execution of the recommendation. Further studies of vaccination behavior in patients with MS are warranted, especially in the light of the current pandemic.

\section{Study Funding}

The authors report no targeted funding.

\section{Disclosure}

All authors report no disclosures relevant to the article. Go to Neurology.org/NN for full disclosures.

\section{Publication History}

Received by Neurology: Neuroimmunology \& Neuroinflammation December 23, 2020. Accepted in final form March 3, 2021.

\section{Appendix Authors}

\begin{tabular}{|c|c|c|}
\hline Name & Location & Contribution \\
\hline $\begin{array}{l}\text { Lara } \\
\text { Diem, MD }\end{array}$ & $\begin{array}{l}\text { Department of Neurology, } \\
\text { Inselspital, Bern University } \\
\text { Hospital and University of } \\
\text { Bern, Freiburgstrasse, } \\
\text { Switzerland }\end{array}$ & $\begin{array}{l}\text { Drafting/revision of the article } \\
\text { for content, including medical } \\
\text { writing for content; major role } \\
\text { in the acquisition of data; study } \\
\text { concept or design; and analysis } \\
\text { or interpretation of data }\end{array}$ \\
\hline
\end{tabular}

Christoph Department of Neurology Drafting/revision of the article

Christoph Department of Neurology, Drafting/revision of the article Friedli, Inselspital, Bern University for content, including medical MD Hospital and University of writing for content Bern, Freiburgstrasse, Switzerland

\begin{tabular}{|c|c|c|}
\hline $\begin{array}{l}\text { Andrew } \\
\text { Chan, MD }\end{array}$ & $\begin{array}{l}\text { Department of Neurology, } \\
\text { Inselspital, Bern University } \\
\text { Hospital and University of } \\
\text { Bern, Freiburgstrasse, } \\
\text { Switzerland }\end{array}$ & $\begin{array}{l}\text { Drafting/revision of the article } \\
\text { for content, including medical } \\
\text { writing for content }\end{array}$ \\
\hline $\begin{array}{l}\text { Anke } \\
\text { Salmen, } \\
\text { PD, MD }\end{array}$ & $\begin{array}{l}\text { Department of Neurology, } \\
\text { Inselspital, Bern University } \\
\text { Hospital and University of } \\
\text { Bern, Freiburgstrasse, } \\
\text { Switzerland }\end{array}$ & $\begin{array}{l}\text { Drafting/revision of the article } \\
\text { for content, including medical } \\
\text { writing for content }\end{array}$ \\
\hline $\begin{array}{l}\text { Robert } \\
\text { Hoepner, } \\
\text { PD, MD }\end{array}$ & $\begin{array}{l}\text { Department of Neurology, } \\
\text { Inselspital, Bern University } \\
\text { Hospital and University of } \\
\text { Bern, Freiburgstrasse, } \\
\text { Switzerland }\end{array}$ & $\begin{array}{l}\text { Drafting/revision of the article } \\
\text { for content, including medical } \\
\text { writing for content; major role } \\
\text { in the acquisition of data; study } \\
\text { concept or design; and analysis } \\
\text { or interpretation of data }\end{array}$ \\
\hline
\end{tabular}

\section{References}

1. Deml MJ, Jafflin K, Merten S, et al. Determinants of vaccine hesitancy in Switzerland: study protocol of a mixed-methods national research programme. BMJ Open. 2019;9:e032218.

2. Bundesamt für Gesundheit (BAG) Pneumokokken Erkrankung. bag.admin.ch/bag/de/ home/krankheiten/krankheiten-im-ueberblick/pneumokokken-erkrankungen.html.

3. Bundesamt für Gesundheit. Schweizerischer Impfplan 2020. bag.admin.ch/bag/de/ home/gesund-leben/gesundheitsfoerderung-und-praevention/impfungen-prophylaxe/schweizerischer-impfplan.html.

4. Williamson EM, Chahin S, Berger JR. Vaccines in multiple sclerosis. Curr Neurol Neurosci Rep. 2016;16:36.

5. McDonald N; the SAGE Working Group on Vaccine Hesitancy. Vaccine hesitancy: definition, scope and determinants. Vaccine. 2015;33:4161-4164. 
6. Streefland P, Chowdhury AM, Ramos-Jimenez P. Patterns of vaccination acceptance. Soc Sci Med. 1999;49:1705-1716.

7. Guay M, Gallagher F, Petit G, Ménard S, Clément P, Boyer G. Pourquoi les couvertures vaccinales chez les nourrissons de l'Estrie sont-elles sous-optimales? Sherbrooke, QC: Centre de santé et de services sociaux - Institut universitaire de gériatrie de Sherbrooke, Direction de la coordination et des affaires académiques; 2009.
9.

Zuzak T, Zuzak-Siegrist I, Rist L, Staubli G, Simoes-Wüst AP. Attitudes towards vaccination: users of complementary and alternative medicine versus non-users. Swiss Med Wkly. 2008;138:713-718. Larson HJ, Cooper LZ, Eskola J, Katz SL, Ratzan S. Addressing the vaccine confidence gap. Lancet. 2011;378:526-535.

10. Wardle C, Singerman E. Too little, too late: social media companies' failure to tackle vaccine misinformation poses a real threat. BMJ. 2021;372:n26. 


\title{
Neurology \\ Neuroimmunology \& Neuroinflammation
}

\author{
Vaccine Hesitancy in Patients With Multiple Sclerosis: Preparing for the SARS-CoV-2 \\ Vaccination Challenge \\ Lara Diem, Christoph Friedli, Andrew Chan, et al. \\ Neurol Neuroimmunol Neuroinflamm 2021;8; \\ DOI 10.1212/NXI.0000000000000991
}

This information is current as of April 2, 2021

\section{Updated Information \& \\ Services}

References

Citations

Subspecialty Collections

Permissions \& Licensing

Reprints including high resolution figures, can be found at:

http://nn.neurology.org/content/8/3/e991.full.html

This article cites 7 articles, 1 of which you can access for free at: http://nn.neurology.org/content/8/3/e991.full.html\#\#ref-list-1

This article has been cited by 1 HighWire-hosted articles: http://nn.neurology.org/content/8/3/e991.full.html\#\#otherarticles

This article, along with others on similar topics, appears in the following collection(s):

Multiple sclerosis

http://nn.neurology.org//cgi/collection/multiple_sclerosis

Information about reproducing this article in parts (figures,tables) or in its entirety can be found online at:

http://nn.neurology.org/misc/about.xhtml\#permissions

Information about ordering reprints can be found online:

http://nn.neurology.org/misc/addir.xhtml\#reprintsus

Neurol Neuroimmunol Neuroinflamm is an official journal of the American Academy of Neurology.

Published since April 2014, it is an open-access, online-only, continuous publication journal. Copyright

Copyright $\odot 2021$ The Author(s). Published by Wolters Kluwer Health, Inc. on behalf of the American

Academy of Neurology.. All rights reserved. Online ISSN: 2332-7812.

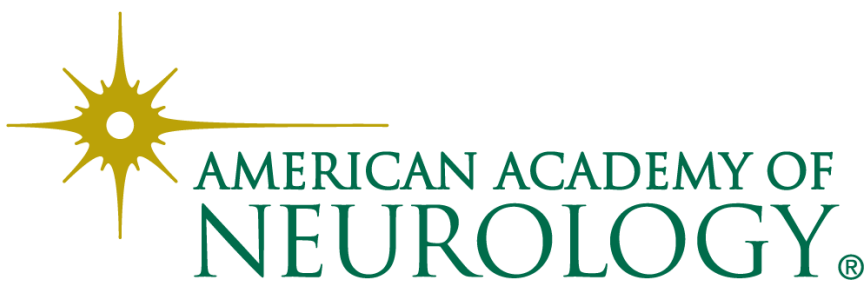

